DOI: https://doi.org/10.3126/njdrs.v15i0.31598

\title{
Changing Pattern of Rural Life and Livelihood: An Ethnographic Investigation
}

\author{
Megh Vilas Bhatta* and Suman Kharel** \\ *Teacher, Department of Humanities and Social Sciences \\ Budhanilkantha School, Kathmandu, Nepal \\ **Faculty member at Central Department of Rural Development
}

Email for correspondence: mv.bhatta@yahoo.com and suman.kharel@cdrd.tu.edu.np

\begin{abstract}
The changing livelihood is an unstoppable phenomenon of the contemporary world at the present era. In the due course of social development, changes have been noticed and the social transformation has become an inevitable process. In the study upon the Aarukharka village, various external interventions like modernity, urbanization and globalization have been found to be the causative factors of ongoing changes in the pattern of people's life and livelihood strategies in the studied community. A qualitative approach backed up by the ethnographic method was applied while various tools and techniques such as elongated stay with the community people followed by key informant interview (KII) and interaction with the participants, observation and discussion were used to gather data. Although change is a dynamic and a common phenomenon, this study implies that the change in the livelihood pattern of the target community is because of the increasing influence of the above mentioned interventions. The finding indicates that livelihood strategies are changing rapidly in the rural areas of Nepal. Despite the fact that the agriculture with livestock farming was an important traditional source of livelihood in the past, the roles of non-agricultural sectors have become significant for livelihood sustaining in the rural communities of Nepal in the present days.
\end{abstract}

Key words: Change, livelihood, occupation, global culture, acculturation

\section{Background}

Nepal is an independent, indivisible, sovereign, secular, inclusive, socialism oriented, federal democratic republican state having multi-ethnic, multi-lingual, multi-religious, multi-cultural characteristics with common aspirations, and being committed to and united by a bond of allegiance to national independence, integrity, national interest and prosperity of Nepal, all the Nepali people collectively constitute the nation (The Constitution of Nepal, 2015). The beautiful country inhabited by the people of various castes and ethnic groups is located on the lap of the panoramic-mighty Himalayas in the southern territory of the Asian continent. "Nepal Char Jat Chhatis Barna ko Sajha Fulbari Ho" (Prithvi Narayan Shah as quoted in Pandey, 2055, p. 68), expresses the fact Nepal being known as the land settled by the people of different ethnic groups, castes and creeds. It is believed that more than that of the government of Nepal declared caste and sub-caste groups of people, others too have settled in different regions of the country having different culture, religion, language, customs, norms and values of their own. 
Despite the existing diversity of the people, they have been wonderfully maintaining social harmony and national unity since the olden days resulting unity in diversity as one of the specified characters of Nepalese culture. People are united by thoughts and are in close rapport among themselves for the sake of nation and nationality, peace and prosperity along with which they have been bringing some changes in their livelihood too. Nepalese culture is variably represented not only by temples and shrines, idols and morals but also by the life style of people and the way they practice their religion, traditional festivals, economic undertakings and much more. In this context, it is most essential to be identified the cultural aspects of different ethnic and caste groups for understanding Nepal as a whole. In the present context of Nepal federalism being executed, the recognition of those diverse characteristics has become fundamentally essential.

It is universal that the social integration among the different castes and religious groups plays a vital role for the progress of the nation. Hence, the social advancement is also necessary things to achieve this; the cultural practices followed by different ethnic groups should be studied and reviewed as cultural capital (Bourdieu as mentioned in Throsby, 1999) for the betterment as well as the sustainable development of the country. The discrimination among the communities has made the provision for the restriction to make any destruction at the harmonious relationship substring among the people of various castes/tribes of communities. The relationship between the economic, social and cultural capital is transformational but non-replaceable.

People's tradition, customs and culture are very important as they form and maintain the identity of them. They should be very conscious to follow their own tradition of religious and cultural values; the traditional practices of communities have been highly evaluated in Nepal because the existence of different tribes and castes cannot be ignored. Therefore, this research study on Aarukharka village of Barpak-Sulikot Gaunpalika, 05, Gorkha is carried out thinking that exposure of the typical ethnic community living here can be helpful to support the process of national integration and thus nation building. Aarukharka village is inhabited by the indigenous Baram community which is one of the significant ethnic groups settled around the hilly regions of Gandaki and Bagmati regions of previous zonal system of Nepal holding an important and significant ethnic position in the population of Nepal, 8,140 in figure (CBS, 2011).

The people from different castes and communities living in the rural areas have different cultural traits and livelihood practices which have been changing day by day with the time call which is very important from sociological/anthropological aspects in the rural development discourse. Varieties of diversified communities of people can be found in the Nepali society of different areas. That's why it can be said that Nepal is a very fertile land for the cultural studies. The study of the social and cultural traits of these diversified communities and societies are not so easy but interesting. The changes always happen in the society as said by Morris Ginsberg "By social change, we understand a change in social structure, e.g. the size of a society, the composition or balance of its parts of type of its organization" (Ginsberg, 1958). In fact, society is a subject to constant changes along with the spinning of time. By defining the socio-cultural change, Kingsley Davis says that it embraces all changes occurring in any branch of culture including art, science, technology, philosophy, etc. as well as changes in the forms and rules of social organization (Davis, 1949). So, this study has tried to find out the changing pattern of life and livelihood strategies as parts of socio-cultural traits in the Baram community of the studied area. 


\section{Objectives}

- To explore the changing life and livelihood strategies of the indigenous Barams in association with their socio-cultural practices.

- To understand modernization effect on Barams' culture, traditions, customs, beliefs, norms and values.

- To document a short ethnography on changing life and livelihood strategies of Barams adopting in the contemporary era.

\section{Methodology}

"The real voyage of discovery is not seeking new landscapes but in having new eyes." -Marcel Proust.

Reflecting upon this statement, we applied ethnographic methodology for look at on changing livelihood parities of Barams. Research methodology is the move towards conducting study to build a new knowledge. It is a process by which a researcher undertakes his/her works of exploring, explaining and predicting phenomena to gain the knowledge. According to Silverman (1993) methodology is a general approach to studying research topics. It is, in fact a detail process a researcher undergoes with bridging the gap and thus connecting the research problem with research methods.

The broad objective of this research paper is to understand the changing pattern of life and livelihood of the indigenous population of Aarukharka in the backdrop of various changes brought by various interventions like modernity, urbanization and globalization. This study has been conducted in ethnographic research design followed by descriptive and interpretive paradigm so that we could describe and analyze the lived experiences of the respondents regarding the gradual change on their livelihood strategies. The ongoing changing pattern of the targeted community was studied in the field by meticulous observation and the required data were collected in the field via informal ethnographic survey (i.e. informal communication, observation \& interview). The research reported here draws on a wide range of published and unpublished sources.

\section{Findings and Discussions: The Context}

Development is a dynamic process; it is never constant and always keeps on happening even though it may be slow or fast (Acharya, Bhatta \& Paneru, 2018). It is preceded by change which is another inevitable phenomenon taking place in and around our societies. Along with the flow of time, change and development seem to have been influencing the life of people everywhere; whether it is in urban or rural area. Moreover, the changing pattern of life and livelihood is seen more significantly in the rural sites. So, it does not seem to be unnatural for the noticeable change in the existing life and livelihood of the Baram community of Aarukharka village of Gorkha district. The following comparative discussion on their traditional and modern life and livelihood activities including locality try to justify the relevancy of the study topic.

\section{Study Area at a Glance}

Since this place is located in remote rural setting, we have an innate relationship with the people of Aarukharka. We also share social-economic linkage with the inhabitants of this locality people. Therefore, we would have ample time to be with them during our visit so that we could be able to handle intensive study on the topic and dig out their perspectives on it. We believed that being an aboriginal of the place; we would be able to shorten the distance among the researchers and research 
participants. Besides that, it is an area of the ward of the Gaunpalika almost totally inhabited by the people of our research community with increasing changes over their traditional living strategies.

This study site i.e. the then ward no. 9 of Takumajh Lakuribot VDC which now lies in ward no. 5 of Barpak-Sulikot Gaunpalika, Aarukharka village is a unique rural place located on the lap of the beautiful hill exposed towards Mt. Manashlu and Himalchuli and at not much high altitude from the eastern bank of River Yashodhara (now known as Daraudi) which is a tributary of River Sapta Gandaki, the deepest river of Nepal. It is further more surrounded by a typical Magar Village called Rana Gaon from the east, Andheri Khola, an un-spoilt small perennial stream in its south and Taku Majhalakuribot village in the north. We selected the place also for the reason that there are so many significantly visible changes taking place in the livelihood strategies of the people in the recent days compared to the past. Moreover, we had to make our research process comfortable and more economic as well.

The pattern of life and livelihood of every indigenous group of people is unique. Thus, the standard of living and common custom of them is exceptional and is related to the utilization of particular natural resource and concentrated to specific type of activities (Guha \& Ismail, 2015). Livelihood may refer to group of requirements which is essential for active and healthy life and it is changed from time to time due to requirement of people (Guha \& Ismail, 2015). A livelihood can also be defined as 'the activities, the assets, and the access that jointly determine the living gained by an individual or household' (Ellis, 1999). A lifestyle is something located at a junction between 'styles of living' and 'living conditions'. But whereas styles of living are determined through personal choices and tastes, and point up the freedom to take decisions affecting one's daily life, living conditions may be seen more as boundaries, marking out the limits of such freedom (Charbonneau \& Gauthier, 2001).

\section{Traditional Pattern of Life and Livelihood}

A livelihood is a means of making a living which encompasses people's capabilities, assets, income and activities required to secure the necessities of life. Livelihood activities are often of various kinds. The bundle of activities is carried out to achieve a certain livelihood can be called livelihood portfolio (Niehof \& Price, 2001). The pattern of life and livelihood of every indigenous group of people is unique. Thus, the standard of living and common custom of them is exceptional and is related to the utilization of particular natural resource and concentrated to specific type of activities (Guha \& Ismail, 2015). Livelihood may refer to group of requirements which is essential for active and healthy life and it is changed from time to time due to requirement of people (Guha \& Ismail, 2015). A livelihood can also be defined as 'the activities, the assets, and the access that jointly determine the living gained by an individual or household' (Ellis, 1999). A lifestyle is something located at a junction between 'styles of living' and 'living conditions'. But whereas styles of living are determined through personal choices and tastes, and point up the freedom to take decisions affecting one's daily life, living conditions may be seen more as boundaries, marking out the limits of such freedom (Charbonneau \& Gauthier, 2001).

Farm based livelihood. The majorities of the world's extremely poor people live in rural areas and have livelihoods which are bound closely to smallholder agriculture as farmers, labourers, transporters, marketers and processors of products and as suppliers of non-agricultural services to households whose income is principally agriculture-derived (Kydd, 2002). Furthermore, the poor in the backwoods are often engaged in the processing and distribution of agricultural products. As Nepal is also still an agricultural country and the study area is located in a remote part of it, farming is the major 
means of livelihood here. About 65 percent people are involved in agriculture in Nepal (Acharya, Bhatta $\&$ Paneru, 2018). Therefore, main source of income of majority of Nepalese people is agriculture and so applies to the people of Aarukharka village as well. Agriculture, vegetables and livestock raising are the major sources of income for rural people livelihood (Poudel, 2017). The following table related to the house hold survey, 2015 reveals the average annual income of Nepalese people from agriculture, vegetables and livestock products which determine the traditional pattern of life and livelihood of the people in Nepal.

Table 1. Average Annual Household Income from Livestock, Agriculture Products

\begin{tabular}{lllllll}
\hline Sources & $\begin{array}{l}\text { Terai } \\
\text { Income }\end{array}$ & Percentage & $\begin{array}{l}\text { Inner Terai } \\
\text { Income } \\
\text { (NRs.) }\end{array}$ & Percentage & $\begin{array}{l}\text { Mid-Hills } \\
\text { Income } \\
\text { (NRs.) }\end{array}$ & Percentage \\
Crops & 43731 & 43.0 & 41500 & 31.7 & 11497 & 33.7 \\
Vegetables & 6283 & 6.2 & 4703 & 3.6 & 1132 & 3.3 \\
Livestock & 51554 & 50.8 & 84776 & 64.7 & 21446 & 62.9 \\
Total & $\mathbf{1 0 1 5 6 8}$ & $\mathbf{1 0 0}$ & $\mathbf{1 3 0 9 7 9}$ & $\mathbf{1 0 0}$ & $\mathbf{3 4 0 7 5}$ & $\mathbf{1 0 0}$ \\
\hline
\end{tabular}

(Household Survey, 2015)

The table 1 indicates that the contribution of animal husbandry or livestock raising is significantly important in earning the livelihood under the traditional pattern of living. It is followed by agricultural crops and vegetable production. In the rural areas of Nepal, diverse activities are carried out by the people to earn the livelihood and run their lives which may be understood as rural livelihood diversification. Rural livelihood diversification is the process by which households construct a diverse portfolio of activities and social support capabilities for survival and in order to improve their standard of living (Ellis, 1999).

Similar to the above condition of the indication of the rural economy through agricultural crops production and livestock raising, the people of Aarukharka village were also traditionally associated with those agricultural activities. Despite the place being located in the hilly areas, lacking very fertile and comfortable lands for the agricultural activities, people used to tilt the land of their own occupied by them around their settlement areas. The sloppy land structured for terrace cultivation, the people used to produce maize and millet as the chief crops but they lacked the paddy production due to lack of plain geography and irrigation facility except in the fertile land located in the basin of River Daraundi and some other wetlands located nearby small streams with the permanent supply of water. In spite of their dependence on agriculture as traditionally major occupation, their production would not be sufficient to feed the familial population throughout the year. The produced grains of maize and millet were mostly used for making jaand i.e. a type of home-made alcoholic drink which is very popular in the local community. Specially, during the agricultural work on the field and before they go to the bed to get refreshed after tiresome work of the day, they prefer to have such jaand almost every day by all the members of the family including the children and the senior citizens.

The following remark made by one of the respondents while interviewing also denotes the popular jaand culture prevailing among the locals of the community. In this regard, a 55 year old man, Dandaghare Mahila, the head of 13 membered joint family (Gharmooli) including father, mother, four sons, three daughters and two unmarried sisters expressed that: 
Gham basyo dandama, man basyo jaandko bhandama. This proud remark clearly indicates the popular jaand culture in the community. Although people say having alcoholic drink is injurious to health, it has been an integral part of this community. Jaand is inevitable for them during the agricultural work on the field, celebrating festivals and performing social other rites and rituals. According to him, it energizes them on the work and also refreshes from exhaustion.

There are many people in the village like Dandaghare Mahila for whom making and drinking jaand is integral aspect of their life. Thus, drinking jaand has become their day to day culture. However, the educated people, these days want to refrain themselves from such habit. Besides, the food grains produced are also consumed as their staple food. Livestock and their products are also common commodities produced in the area. The main livestock include: cows (milk production), buffaloes (milk and meat), bulls/oxen (for ploughing), sheep and goats, poultry and apiculture. Like agriculture, livestock raising is also carried out in Aarukharka for subsistence purpose only; it is not commercialized.

Family system. An individual is a basic entity of the society who cannot be understood in isolation from one another. Rather than the family just being known only as the group of individuals, strong emotional bonding works as the prime factor to form a family. Therefore, families are systems of interconnected and interdependent individuals, none of whom can be understood in isolation from the system (Bowen, 1952). In the local community of the studied area, traditionally they used to have joint family system with strong emotional bonding among the members of at least three generations unitedly living together under the same roofs enjoying the single kitchen.

According to Merriam Webster online dictionary (since 1828), joint family is a consanguineal family unit that includes two or more generations of kindred related through either the paternal or maternal line who maintain a common residence and are subject to common social, economic, and religious regulations. In the traditional joint family system, family income flows into a common pool, from which resources are drawn to meet the needs of all members, which are regulated by the heads of the family. However, with urbanization and economic development, recently Nepal has witnessed a tragic break up of traditional joint family into more nuclear-like families, and such families are accounted for a small number of households.

Income generation. We observed them being involved in various traditional local activities for their livelihood rather than cash generation activities. The community was characterized as a working class; hence their livelihood was based on self-cultivation, parma and wage earning work on daily basis. The following remarks of an informant made during an informal communication also help us develop a concept on their irregular and limited income generation activities based on occasions which has been broadened these days:

Haamro palama lahur jaane chalan thiyan, ahile bahir desh jaane bhanchha. Ahileka thitathitiharu gau chhoder sahar jaana man parauchha. Desh-bidesh gako chha. Tara uhileko budhaharu ta yatai gaugharma kaam garthyo. Kohi karmi kaam garthyo, kohi machha marthyo, bibah karjema dola boker, bhari boker pani kamauthyo. Khasi, boka, kukhura becher pani kamauthyo tara ahile tyo jamana kata gayo kata?

Along with the learning through our prolonged observation, the above remarks of the informant 
of the studied community are sufficient to perceive that there is massive influence of the livelihood changing factors like modernity, urbanization and globalization. Not only this but many other people who interacted with us during our several visits to the locality, also did not deny the fact. The earlier simple life of those innocent people is gradually changing into and catching a complex trend inspired by cash income. It can be observed that many people of the studied community are attracted towards regular salary based various works in the cities, foreign countries, teaching service and security service (police and army).

\section{Changing Pattern of Life and Livelihood}

Mainly, transformation of livelihood strategies in the recent days seems caused by education and awareness, modernity, urbanization and globalization. These things open new opportunities for employment and multiple sources of income for the local people. Multiple income sources are more secured than single one in any situation (Chambers and Conway, 1992 as mentioned in Rai, 2017). It can be said that since Nepalese rural villages are experiencing a transition from tradition to modernity or even postmodernity, different aspects of lifestyle are somehow mingled; young people in rural areas show a tendency toward urban lifestyle while older people prefer local rural lifestyle (Qeidari, Sadeglou \& Shahadadi, 2015). River Daraudi is flowing unstoppably, the dark forest of Kalodhunga is standing still and the gentle sireto from Manashlu and Himalchuli is tickling the people of Aarukharka along with which they are also adapting the changes from farm-livelihood to non-farm livelihood.

Modernity and livelihood. Modernity can be understood as a condition of social existence that is significantly different to all past forms of human experience that comes through modernization which is an encompassing process of massive social changes (Inglehart \& Welzel, 2007). Under this section, economy based modernity shall be focused in terms of the findings of the study. Here, we are not talking about the modernization process of agriculture but the increasing trend of giving up of the agricultural profession is what people have wrongly understood as modernity. It has been a big misfortune for the country's economy that people understand agriculture as a traditional occupation and not adopting it is being a modern. Similar is the notion of the people of Aarukharka village too. During the interaction as a part of our study, almost all discussants admitted that interest of their children to take over farming is low. Farmers themselves expect their children to be educated and engage in nonfarm sectors or work in formal sectors in urban areas. A woman discussant expressed her feelings as:

I don't wish for my children to engage in farming like me. However, they may not have other option if they are unemployed or could not get jobs in non-farm sectors.

With such a strong realization, people are switching from farm based (so called traditional) to non-farm-based (so called modern) livelihood. Although farm-based economy is the major component of earning livelihood in the rural areas in almost all parts of Nepal and production of agricultural crops and livestock raising provide lifeline to the most population of countryside, the people of Aarukharka village are attracted towards the modern non-farm economic activities. Not only this, even the traditional non-farm activities are also forsaken by the people for the cause of modern non-farm activities. These days, there has been increasing recognition that the rural economy is not confined to the agricultural sector only, but embraces all the people, economic activities, infrastructure and natural resources in rural areas (Csaki \& Lerman, 2000). Equally, rural livelihoods are not limited to income derived solely from agriculture but may derive from diverse sources (Ellis, 1998, p. 6). It cannot be 
considered homogenous; rather it is characterized by its heterogeneity, incorporating self-employment, micro-, small- or medium-sized enterprises (MSMEs) and trade activities (Davis, 2006). The early non-farm livelihood activities of the people of Aarukharka village were significantly based on fishing, forestry and porterage. In the same theme, reflections of the participant have been presented below:

According to Indrajit Baram (name changed), also called as Mukhiya Baram (75), he used to go to the River Daraundi for fishing. Specially, during the rainy seasons he collected Asala and Buduna which would come to his paddy field searching for fresh water due to the muddy flood in the river. In contrast, during the dry season in the months of Chaitra, Baisakh and Jestha, when the volume of water would be small in the river, he used to catch the fish by diverting the river and using some kinds of vegetative leaves poisonous to fish.

As this song says "Saune khola urler aaunda, machhi marne duwali chheker..., tarki najau baisalu joban ma ta aaye timilai dekher", both males and females worked hard together to divert the flow of river (called as duwali chheknu) entertaining among themselves by singing such songs of love and affection, to catch fish and to earn their livelihood. They used Dhadiya, Khunga, Furlung, Jaal (fishing net) etc. for fishing purpose which they used to produce at home as handicraft products by themselves.

Similarly, their traditional livelihood was also dependent on forestry. Since his agricultural products were not sufficient to feed them, his family members used to collect some raw root and tuber crops like Gittha, Bhyakur etc. to consume. They also cut the trees to obtain timber, furniture, agricultural tool like plough, yolk etc. They also collected larvae of various types of insects like wasp, hornet etc. including the collection of honey of bee from the forest. Thus, forest related activities were also helping them to earn the livelihood in the community. According to Mukhiya, the people were also involved in another non-farm wage earning occupation through porterage.

There were many other people in Arukharka like Mukhiya who had diverse experience of traditional non-farm livelihood strategy. But these days, such activities have been noticed as declining. There is an increasing trend of the people migrating to the urban areas in the pretention of providing good education to their children in the urban areas. Interaction with other young people of the community gave us an impression that in the recent days, the farm-based activities like growing crops and livestock raising are becoming unpopular among the youngsters. So, the young populations are found being attracted towards non-farm works. While listening to them, we came to learn that nonfarm work is preferred by almost all people because, as the common villagers put it: "agriculture makes hand dirty."

Globalization and livelihood. The modern era is characterized by rapid growth in the international connectivity resulting into the development of a commonly adaptable culture called as the global culture. The people at the modern generation have started adopting and getting assimilated with the global culture which increasingly seems to have been flourishing in the urban regions. Yakubu (1999) discovers that young people of the third world countries are the largest consumers of global culture. Such an acculturation process seems to be taking place in rural to urban regions and developing to developed countries. Many factors like political changes, growth of international and regional mechanism of government and intergovernmental organizations (IGOs) and international non-governmental organizations (INGOs) are found jumping as driving forces leading to intensifying 
globalization (Giddens, 2001, p. 55). The people of Aarukharka have also been affected by acculturation due to their movement towards urban areas for non-agricultural income generation and abroad for remittance. The following narrations also support connection between globalization and livelihood:

Chhora bahir desh gako chha, Abudhabi ma chha, paisa pathaidinchha kahilekahi. Kaam nagar bhanchha. Haami aba nasakne bhaehalyo. Ke garne? Dudh, mohi khana man ta lagchha ni tara bastu paalna sakdaina.

Listening to the remarks made by Gairaghare Kanchha, anyone can easily assume that the wave of globalization is thrashing the people of the world, specially the people of the poor and developing countries like ours compelling to adopt the so called modern way of life i.e. the life with imported identity forgetting the indigenous identity.

Urbanization and livelihood. Urbanization has become an increasing trend across the world and urban settlement has become a very lucrative attitude of the human population today. Consequently, there seems a prompt growth of cities and with them a growing internal market, rising population and the general extension of transport, bringing cheap manufactured consumer goods and agriculture, elements of production to the rural zone, in exchange for money and a much greater and more consistent demand for agricultural products rather than random invasion (Bhattarai \& Bhattarai, 2003). Such a process may be known as urbanization and hence urbanization indicates to a process of standardization of rural region, turning them into cities; thus, an increasing proportion of an entire population lives in cities and the suburbs of cities. Thus, the process of urbanization is a relatively recent phenomenon in which there is a switch from a spread-out human settlement to one of concentration in urban centers (Davis as mentioned in Giddens, 2001). In this process, a new rural middle stratum begins to acquire identity, adopting behaviours and symbols taken from urban life based on three dimensions viz economic, structural and cultural dimensions (Bhattarai \& Bhattarai, 2003).

Urbanization effect on changing life and livelihood has not become an exception with the people of our study area too. The younger generation including male and female, married and/or unmarried are caught in rat race to leave their place of origination getting attracted towards urban settlement permanently and or non-permanently with the pretext of several reasons like job, children's education, small entrepreneurship, daily wage based work etc. The successors of the indigenous settlers of Aarukharka are found spending lesser time maintaining interpersonal relations with their predecessors while at the same time, they are also heard expressing satisfaction and proud feeling upon the children's settlement in the urban areas even if they are getting lonelier and vulnerable due to their detachment with children. Familial relationships are getting fractured and motives turning selfish while the senior citizens are forced to rely on social security allowances provided by the government.

\section{Conclusion}

In conclusion, it can be noted that there is increasing trend in Nepal regarding the rural life and livelihood changing process while the same has happened in Aarukharka village too. Although change in life and livelihood of people at a place is a lively phenomenon, many external agents appear to have been playing a significant role behind the change of life and livelihood strategy of the people at a certain place. Aarukharka is one of those several rural areas of Nepal inhabited by Baram people, also known as Baramu who are one of those highly marginalized indigenous communities recognized by the government of Nepal. Significant changes have been noticed in their traditional farm-based 
livelihood, family system and income generating activities into the diversified livelihood pattern under the influence of modernity, urbanization and globalization. An intergenerational clash is seen with respect to the changing of life and livelihood between the older population and their new generation while the earlier preferring the traditional rural life and livelihood but the latter's preference is towards modern, urban and globalized pattern of life and livelihood. The noticeable transformation from farm based livelihood to non-farm based livelihood, joint family system to nuclear family system, local strategies of income generation to the adoption of global strategies along with the practice of diversified measures of life and livelihood rationalize the ongoing change on life and livelihood pattern of the people in Aarukharka village of Gorkha.

\section{References}

Acharya, H. N., Bhatta, M. V., \& Paneru, N. P. (2018). Vidyarthi's social studies and population education. Book 6. Kathmandu: Vidyarthi Pustak Bhandar.

Bhattarai, T., \& Bhattarai, S. (2003). Perspectives on social change and cultural change and development. Kathmandu: National Book Centre.

Bowen, M. (1952). The family system theory. International Social Service (ISS) Family Institute.

Central Bureau of Statistics (CBS). (2011). National population and housing census. Kathmandu: Author

Charbonneau, J., \& Gauthier, M. (2001). Introduction: Culture and lifestyle. Loisir et Société, 24(2), 353-356. doi.org/10.7202/000186ar

Csaki, C., \& Lerman, Z. (2000). Agricultural transition revisited: Issues of land reform and farm restructuring in East Central Europe and the former USSR. Washington DC: World Bank.

Davis, J. (2006). Rural non-farm livelihoods in transition economies: emerging issues and policies. Electronic Journal of Agricultural and Development Economics (EJADE), 3(2), 180-224.

Davis, K. (1949). Human society. New York: The Macmillan Company.

Ellis, F. (1998). Rural livelihood diversification: Framework and categories. (Unpublished mimeo). Chatham, UK: Natural Resources Institute.

Ellis, F. (1999). Rural livelihood diversity in developing countries: Evidence and policy implications. London, UK: Overseas Development Institute (ODI).

Giddens, A. (2001). Sociology. London, UK: Polity Press in Association with Balckwell Publishers Ltd.

Ginsberg, M. (1958). Social change. Bobbs-Merrill Reprint Series in the Social Sciences, S 581.

Government of Nepal, MoLJPA. (2015). The constitution of Nepal. Kathmandu: Author.

Guha, S., \& Ismail, M. (2015). Changing pattern of life and livelihood through environment at Sonajhuri Village of Santiniketan in Birhbum District of West Bengal. International Research Journal of Social Sciences, 4(7), 33-40.

Inglehart, R., \& Welzel, C. (2007). Modernization. Retrieved from https//www.researchgate.net/ publication/236749001.

Kydd, J. (2002). Agriculture and rural livelihoods: is globalization opening or blocking paths out of rural poverty? London: Imperial College. 
Niehof, A., \& Price, L. (2001). Rural livelihood system: A conceptual framework. UPWARD Working Paper Series, No. 5. WU-UPWARD, Wageningen.

Pandey, R. K. (2055). Nepal parichaya. Kathmandu: Bhundipuran Prakashan.

Poudel, D. P. (2017). Livelihood strategy of community forest users: A case from nawalparasi district. Nepalese Journal of Development and Rural Studies, 14(1\&2), 21-27.

Qeidari, H. S., Sadeglou, T., \& Shahdadi, T. (2015). The effects of globalization on lifestyle changes in rural areas. doi: 10.7508/isih.2015.28.006

Rai, D. B. (2017). Changing rural livelihood strategies in the community of Goljung, Rasuwa. The Third Pole Journal of Geography, 17, 20-36, 2017. Department of Geography Education, Central Department of Education, TU, Kathmandu.

Silverman, D. (1993). Interpreting qualitative data. London: Thousand Oak Publication.

Throsby, D. (1999). Cultural Capital. Journal of Cultural Economics. 23(1), 3-12. doi: 10.1023/A: 1007543313370

Yakubu, N. (1999). Millenium and globalization: What is in it for us? Crystal International News Magazine, p. 35. 